\title{
Research protocol of the NeedYD-study (Needs in Young onset Dementia): a prospective cohort study on the needs and course of early onset dementia
}

Deliane van Vliet ${ }^{1}$, Christian Bakker ${ }^{2,3}$, Raymond TCM Koopmans ${ }^{3}$, Myrra JFJ Vernooij-Dassen ${ }^{4,5}$, Frans RJ Verhey ${ }^{1}$, Marjolein E de Vugt ${ }^{*}$

\begin{abstract}
Background: Early onset dementia has serious consequences for patients and their family members. Although there has been growing attention for this patient group, health care services are still mainly targeted at the elderly. Specific knowledge of the needs of early onset dementia patients and their families is limited but necessary for the development of adequate health care services and specific guidelines. This research project is mainly targeted at delineating the course of early onset dementia, the functional characteristics and needs of early onset dementia patients and their caregivers, the risk factors for institutionalization and the interaction with the caring environment.
\end{abstract}

Methods/Design: The NeedYD-study (Needs in Young Onset Dementia) is a longitudinal observational study investigating early onset dementia patients and their caregivers $(n=217)$. Assessments are performed every six months over two years and consist of interviews and questionnaires with patients and caregivers. The main outcomes are (1) the needs of patients and caregivers, as measured by the Camberwell Assessment of Needs for the Elderly (CANE) and (2) neuropsychiatric symptoms, as measured by the NeuroPsychiatric Inventory (NPI). Qualitative analyses will be performed in order to obtain more in-depth information on the experiences of EOD patients and their family members. The results of this study will be compared with comparable data on late onset dementia from a historical cohort.

Discussion: The study protocol of the NeedYD-study is presented here. To our knowledge, this study is the first prospective cohort study in this research area. Although some limitations exist, these do not outweigh the strong points of this study design.

\section{Background}

Dementia is often regarded as a disease of old age. However, there is also a group in which the symptoms of the disease develop before the age of 65 . Prevalence rates of early onset dementia (EOD) have been reported to range between 54 and 260 cases per 100,000 in the 30-64 age group [1-3].

EOD is recognized as an important psychosocial and medical health problem with serious consequences for

\footnotetext{
* Correspondence: m.devugt@maastrichtuniversity.nl

${ }^{1}$ School for Mental Health and Neuroscience, Alzheimer Center Limburg, Maastricht University Medical Center, Maastricht, the Netherlands
}

patients and their families [4,5]. EOD is more difficult to recognize than late onset dementia (LOD) in the early stages of the disease because of the lower prevalence rate, the wider range of etiologies [6,7] and the use of other mental health services (e.g., community mental health teams). These factors cause an important delay before an accurate diagnosis can be established, commonly resulting in feelings of insecurity and frustration for both patients and their families [8]. A proper diagnosis is an important prerequisite for receiving adequate (in)formal support and health care services.

EOD also may have a different clinical manifestation than LOD due to the relatively high prevalence rate of

\section{C) Biomed Central}


frontotemporal dementia (FTD), in which problem behavior is more prevalent as the presenting sign of probable dementia [6,7]. Recent research on the impact of problem behavior on caregivers and vice versa shows that these specific aspects of the dementia, more so than cognitive and functional changes, have severe consequences for patients and their family members [9]. Problem behavior is the most important risk factor for caregiver burden and is a strong predictor of institutionalization [10-12] but is also an important starting point for interventions [13]. Recent studies have shown that psychological factors, such as disease awareness [14], and environmental factors, such as caregiver management strategies [15], influence the development and persistence of problem behavior in LOD. Similar studies on EOD have not yet been conducted.

Furthermore, EOD patients are in a life phase in which they often have an active role in society and often have young children. The loss of roles and responsibilities is, therefore, greater than in older people. They also have to deal with specific issues such as marital problems, family conflict, (un)employment and financial issues [5]. Furthermore, many EOD patients of the postwar baby boom generation grew up in a society that is very different from that of the older generation. The needs of EOD patients may, therefore, be different and demand a different approach than in LOD.

Despite these differences, the availability of specialized healthcare services is still limited in most countries, forcing EOD patients and their family members to use services designed for the elderly. In the Netherlands, specialized services are available, but their geographic distribution is limited, as is the range of services offered. Furthermore, specific knowledge on the characteristics and needs of EOD patients and their families is lacking but prerequisite for the development of suitable health care services. Adequate diagnostics, (in)formal support and services like support groups, day care facilities or respite care may help patients and their families cope with the situation and may even postpone institutionalization. This multidisciplinary research project focuses on the course of EOD, the functional characteristics of EOD patients, the needs of EOD patients and their caregivers, the risk factors for institutionalization and the interaction with the caring environment. We expect that the study will yield important data that can be used to design specific guidelines and improve the development of health care services for EOD patients and their families.

\section{Aim and research questions}

NeedYD is a prospective cohort study with the following primary objectives: (1) to investigate the (un)met needs of EOD patients and their family members during different phases in the course of the disease (e.g., the diagnostic phase and the phase in which (specialized) day care is provided) and (2) to investigate the course of neuropsychiatric symptoms and possible risk factors (i.e., comorbidity, age, communication problems, biological factors, disease awareness, interaction with the environment).

The secondary objectives are:

- To gain insight into the course of other functional domains in EOD (cognition, activities of daily living); - To explore the experiences and feelings of patients and their caregivers during the diagnostic period;

- To investigate the impact of the diagnosis of dementia on EOD patients and their family members;

- To study the course of the functioning of the caregivers of EOD patients and the problems they (and possibly other family members) experience;

- To identify factors that influence the use of respite care and determine institutionalization;

- To explore to what extent stigma and taboo concerning dementia interfere with adequate communication within the family;

- To compare these findings with findings of studies on LOD.

\section{Methods/Design}

\section{Design}

The NeedYD-study is a prospective cohort study with a follow-up of two years in which a group of EOD patients and their families are assessed at six month intervals. The study design is similar to that of the MAAstricht Study of BEhavior in Dementia (MAASBED) and the WAAL BEhavior in Dementia (WAALBED) study [16-19] conducted in the Netherlands.

\section{Subjects}

The study population consists of dyads of patients with EOD and their caregivers. Patients with onset of disease symptoms before the age of 65 are included in the study (age at inclusion could be later than 65). Diagnoses of dementia subtype are made according to regular criteria [20-25]. Patients are recruited through the memory clinics of the three Alzheimer's centers in the Netherlands located in Amsterdam, Nijmegen and Maastricht, the memory clinics of general hospitals and through other mental health services in the south of the Netherlands as well as through specialized day care facilities that are affiliated with the Dutch National EOD Taskforce. Thus, a group of patients without day care or receiving nonspecialized day care, as well as a group of patients receiving specialized day care, are included in the study. For 
some of the research questions, these groups will be compared. The exclusion criteria are: (1) dementia caused by HIV, traumatic brain injury, Down's syndrome, Huntington's chorea or alcohol-related dementia, (2) lack of a reliable informant or (3) lack of informed consent of the participant. Furthermore, children of EOD patients who are living at home and are older than 14 years of age at the time of the baseline assessments are recruited through their parents.

\section{Measures}

\section{Primary outcome measures}

(Un)met needs are assessed with the Dutch version of the Camberwell Assessment of Needs in the Elderly (CANE) [26]. This assessment is a semi-structured interview consisting of 24 domains that cover social, physical, psychological and environmental needs. The interview starts with an open question concerning a specific domain, followed by questions regarding help and (in) formal support the patient receives in that particular domain, as well as the amount of help and support that is needed. These items are scored on a three point scale ranging from little (1) to a lot of help (3). Satisfaction with the amount and quality of the help and support received is also assessed. The answers are used to determine whether or not the participant experiences a need and whether or not this need is met. The experienced needs of patients are based on patient and proxy (primary caregiver) interviews. The need for information and the psychological needs of the caregiver are also assessed by means of the CANE. Reliability and validity were found to be adequate [26].

Neuropsychiatric symptoms in the patient and related caregiver burden are assessed with the Dutch version of the Neuropsychiatric Inventory (NPI) [27]. The NPI is a structured interview with the primary caregiver and, when available, a health care professional. After institutionalization, the nursing home version of the NPI (NPI-NH) is used [28]. Ten neuropsychiatric and two neuro-vegetative symptoms are assessed: delusions, hallucinations, agitation/aggression, dysphoria, anxiety, euphoria, apathy, disinhibition, irritability/lability, aberrant motor behavior, night-time behavior disturbances and appetite/eating abnormalities. Screening questions are asked to determine whether behavioral changes are present. In the case of a positive answer, further questions are asked and the severity and frequency of the behavioral disturbances are determined. The Dutch version of the NPI has high inter-rater agreement and is found to be a valid rating scale for measuring a wide range of behavioral and psychological symptoms of dementia [29]. Furthermore, the experience of caregiver distress due to these neuropsychiatric symptoms is determined according to the six point NPI caregiver distress scale (NPI-D) ranging from no distress (0) to extreme distress (5) [30]. The NPI-D provides a reliable and valid measure of subjective caregiver distress in relation to the neuropsychiatric symptoms measured by the NPI.

For an overview of all measurements see Table 1.

\section{Secondary outcome measures for the patient}

The Global Deterioration Scale (GDS) is administered to assess the severity of the dementia. The GDS is a widely used instrument which has been validated against behavioral, neuro-anatomic and neurophysiologic measures, for which significant correlations have been found [31]. The Interview for Deterioration in Daily Living in Dementia (IDDD) is used to assess the activities of daily living. The internal consistency of this scale is high (Cronbach's alpha 0.94) [32]. Cognitive functioning is measured using the Mini Mental State Examination (MMSE), which is a reliable and valid test of cognitive function [33]. When the MMSE score is below 15, the Short Severe Impairment Battery (s-SIB) is administered, which has been found to be a reliable and valid test of cognitive function in moderate to severe dementia patients [34,35]. Furthermore, executive functioning is assessed using the Frontal Assessment Battery (FAB). The FAB has good inter-rater reliability, internal consistency and discriminant validity [36]. The Guidelines for the Rating of Awareness of Deficits (GRAD) [37,38] are administered in order to investigate disease awareness. This instrument has substantial inter-rater reliability [39]. The Quality of Life-Alzheimer's Disease scale (QoL-AD), which has good content, criterion and construct validity and excellent inter-rater reliability and internal consistency [40], is used to assess the quality of life of the patient, as perceived by the patient and his caregiver. The Cornell Scale for Depression in Dementia (CSDD) [41] is administered to identify depressive symptoms in the patient. This scale has adequate interrater reliability, internal consistency and sensitivity. The amount of formal care the patient receives and the time the caregiver spends caring for the patient are obtained using the Resource Utilization Scale (RUD-Lite), which covers $95 \%$ of the resource use, the complete RUD covers [42]. Therefore, it is a good alternative for the complete RUD when the assessment battery is large.

\section{Secondary outcome measures for the caregiver}

The Short Sense of Competence Questionnaire (SSCQ) [43] is administered to assess caregiver's feelings of being capable to care for a demented individual. The SSCQ was reported to have satisfactory reliability and validity [43]. Depressive symptoms are measured by the Montgomery Asberg Depression Rating Scale (MADRS), which has adequate inter-rater reliability and exhibits construct and concurrent validity [44]. Psychological and physical complaints are measured with the 
Symptom Checklist 90 (SCL-90). Reliability and construct validity of the SCL-90 are satisfactory [45]. Emotional instability is assessed with the neuroticism subscale of the Dutch version of the NEO-Five Factor Inventory (NEO-FF-I). Internal consistency and test-retest reliability are high for this scale, as is the construct validity [46]. Coping strategies are assessed by means of the Utrechtse Copinglijst (UCL). The reliability of this scale is reasonable and the validity has been found to be sufficient despite some inconsistencies in the literature [47]. General health is measured with the Dutch translation of the RAND-36 [48]. The Dutch version of the RAND-36 appears to be a reliable, valid and sensitive measure for general health [49]. In addition, the quality of the marital relationship and the changes that have occurred since the onset of the disease are measured by four items of the University of Southern California Longitudinal Study of Three-Generation Families measures of positive affect. Cronbach's alpha for this scale is 0.85 [50]. The caregiver management strategy is assessed by means of questions reflecting three caregiver strategies: a caring, supporting or non-adapting strategy [15]. This scale has not yet been validated. Furthermore, a semi-structured interview is administered to the caregiver and, when applicable, to children living at home. The interview includes topics concerning the period prior to diagnosis, the impact of the diagnosis, changes in the interpersonal relationships within the family, the communication within the family about the disease, the problems experienced by the patient and family members, experiences and beliefs concerning (in)formal support and health care services, transitions in care (e.g., day care, institutionalization) and future perspectives.

\section{Additional data}

By means of a structured interview and examining the patients file information, medical and demographical information of the patient are obtained. For a full description of these data, see Table 1.

\section{Procedures}

EOD patients and their caregivers receive five assessments at six-month intervals (B, F1, F2, F3, F4; Table 1). Before inclusion in the study, (S) information on in/ exclusion criteria is collected and informed consent is obtained. Patients who are not able to sign informed consent are asked to give oral consent and their legal representative has to give written consent that the patient can participate. Children living at home who are older than age 14 are asked at baseline to participate in a semi-structured interview. Children aged between 15 and 18 years, as well as their legal representatives, both have to sign informed consent. When individuals do not agree to participate, the reason plus age, gender and diagnosis of the patients are registered.
When participants, after inclusion in the study, do not wish to participate in one of the assessments, caregivers are asked to participate in an interview by telephone, so the CANE, NPI and Sense of Competence questionnaire can be administered and to fill out all of the questionnaires required for that assessment. If this is not possible, the researcher asks them to answer several questions about their own and the patients' functioning and about the use of formal care. If caregivers refuse this as well, the reason for refusal is asked. When a patient has died, data on the use of (in)formal care and the needs of caregivers before and after the patient died is collected from the caregiver as well as the date and cause of death.

\section{Ethical considerations}

The study protocol is approved by the Medical Ethics Committee of the University Medical Center Maastricht. The local ethics committees of the participating institutions have also given consent. The research project is performed according to the principles of the Declaration of Helsinki (version January 2004; http://www.wma.net) and in agreement with the law regarding medicalscientific research in humans (WMO). An independent physician is assigned to the study. Participants are informed about the possibility of contacting him for further questions about the study.

\section{Sample size}

Based on a power calculation (two groups: diagnostic phase and the phase of specialized day care; ANOVA) with an alpha of 0.05 , a power of 0.85 and an expected effect size of $0.25,128$ EOD patients are required to participate in the study. With an expected loss to follow-up of $37 \%$ in a two year follow-up period based on data of the MAAstricht Study of BEhavior in Dementia (MAASBED) study [15], 200 patients need to be included.

\section{Data analysis}

Data entry is performed twice to safeguard data integrity. Statistical analyses will be performed using the Statistical Package for Social Sciences, version 17. Descriptive statistics will be used to describe characteristics of patients and caregivers, i.e., age, sex, distribution of diagnoses, etc. Both quantitative and qualitative data will be used in the analyses.

Diagnosis matched patients with LOD from a historical cohort (MAASBED study) will be used to make a comparison with EOD. Baseline differences between groups will be analyzed to investigate the comparability of the groups. Depending on the research question and which variables will be analyzed, parametric or nonparametric analyses will be performed. Comparisons 
Table 1 Flowchart of measures used during the assessments

\begin{tabular}{|c|c|c|c|c|c|c|c|}
\hline \multirow{2}{*}{$\begin{array}{l}\text { Outcome measure } \\
\text { Patient }\end{array}$} & \multirow{2}{*}{$\begin{array}{l}\text { Operationalization } \\
\text { (Type of instrument) }\end{array}$} & \multicolumn{6}{|c|}{ Time of assessment } \\
\hline & & $S$ & B & F1 & F2 & F3 & F4 \\
\hline \multicolumn{8}{|l|}{ Primary outcomes } \\
\hline Needs & CANE [26] (SSI) & & $\mathrm{P} / \mathrm{C}$ & $P / C$ & $\mathrm{P} / \mathrm{C}$ & $\mathrm{P} / \mathrm{C}$ & $\mathrm{P} / \mathrm{C}$ \\
\hline $\begin{array}{l}\text { Frequency and severity } \\
\text { neuropsychiatric symptoms }\end{array}$ & $\begin{array}{l}\text { NPI [27] } \\
\text { NPI-NH [28] (SI) }\end{array}$ & & $\mathrm{C} / \mathrm{N}$ & $\mathrm{C} / \mathrm{N}$ & $\mathrm{C} / \mathrm{N}$ & $\mathrm{C} / \mathrm{N}$ & $\mathrm{C} / \mathrm{N}$ \\
\hline \multicolumn{8}{|l|}{ Secondary outcomes } \\
\hline Severity of dementia & GDS [31] (RS) & & $\mathrm{C} / \mathrm{P}$ & $C / P$ & $C / P$ & $C / P$ & $C / P$ \\
\hline Depressive symptoms & CSDD [41] (SI) & & C & C & C & C & C \\
\hline Cognitive functioning & MMSE [33] (CT) & & $P$ & $P$ & $P$ & $P$ & $P$ \\
\hline Cognitive functioning & SIB [34] If MMSE <15 (CT) & & $P$ & $P$ & $P$ & $P$ & $P$ \\
\hline Executive functioning & FAB [36] (CT) & & $P$ & & $P$ & & $P$ \\
\hline ADL disabilities & IDDD [32] (Q) & & C & & C & & C \\
\hline Disease awareness & GRAD [37,38] (SSI) & & $\mathrm{C} / \mathrm{P}$ & $C / P$ & $C / P$ & $C / P$ & $C / P$ \\
\hline Amount of formal and informal care & RUD-lite [42] (SI) & & C & C & C & C & $C$ \\
\hline Quality of life & QoL-AD [40] (SI/Q) & & $\mathrm{C} / \mathrm{P}$ & $C / P$ & $C / P$ & $C / P$ & $C / P$ \\
\hline \multicolumn{8}{|l|}{ Additional variables } \\
\hline Inclusion/exclusion criteria & & $\mathrm{R} / \mathrm{P} / \mathrm{C}$ & & & & & \\
\hline Informed Consent & & $\mathrm{P} / \mathrm{C}$ & & & & & \\
\hline Demographic data & $\begin{array}{l}\text { Age, gender, education level, marital status, } \\
\text { employment }\end{array}$ & & $\mathrm{P} / \mathrm{C}$ & & & & \\
\hline Diagnosis & $\begin{array}{l}\text { First complaints, date of diagnosis, physician } \\
\text { that gave diagnosis }\end{array}$ & & $\mathrm{P} / \mathrm{C}$ & & & & \\
\hline Life events & $\begin{array}{l}\text { Disease, institutionalization, conflict, divorce, } \\
\text { other }\end{array}$ & & $\mathrm{P} / \mathrm{C}$ & $P / C$ & $\mathrm{P} / \mathrm{C}$ & $\mathrm{P} / \mathrm{C}$ & $\mathrm{P} / \mathrm{C}$ \\
\hline Medical record investigation & $\begin{array}{l}\text { Current diagnosis, possible prior diagnoses, } \\
\text { examinations that lead to diagnosis, medical } \\
\text { history }\end{array}$ & & $\mathrm{R}$ & & & & \\
\hline Treatment and other information & $\begin{array}{l}\text { Physical complaints, current treatment/use } \\
\text { of formal care, medical history, substance } \\
\text { use, dementia/genetic diseases in family }\end{array}$ & & $\mathrm{P} / \mathrm{C}$ & $\mathrm{P} / \mathrm{C}$ & $\mathrm{P} / \mathrm{C}$ & $\mathrm{P} / \mathrm{C}$ & $\mathrm{P} / \mathrm{C}$ \\
\hline \multicolumn{8}{|l|}{ Caregiver } \\
\hline \multicolumn{8}{|l|}{ Primary outcomes } \\
\hline Needs & CANE [26] (SSI) & & C & C & C & C & C \\
\hline $\begin{array}{l}\text { Experienced burden as a result of } \\
\text { behavioral disturbances }\end{array}$ & NPI [27] (SI) & & $\mathrm{C} / \mathrm{N}$ & $\mathrm{C} / \mathrm{N}$ & $\mathrm{C} / \mathrm{N}$ & $\mathrm{C} / \mathrm{N}$ & $\mathrm{C} / \mathrm{N}$ \\
\hline Needs and experiences & $(\mathrm{SSI})$ & & C & & C & & C \\
\hline Sense of competence & SSCQ [43] (SI) & & C & C & C & C & $C$ \\
\hline \multicolumn{8}{|l|}{ Secondary outcomes } \\
\hline Depressive symptoms & MADRS [44]. (SI) & & C & & C & & C \\
\hline $\begin{array}{l}\text { Psychological and somatic } \\
\text { complaints }\end{array}$ & SCL-90 [45] (Q) & & C & C & C & C & C \\
\hline Coping strategies & UCL (Schreurs, Willige et al. 1988) (Q) & & C & & & & \\
\hline Quality of life & RAND-36 [48] (Q) & & C & & C & & C \\
\hline Quality of the marital relationship & $\begin{array}{l}\text { Four items of the University of Southern } \\
\text { California Longitudinal Study of Three- } \\
\text { Generation Families measures of positive } \\
\text { affect [50]. (Q) }\end{array}$ & & C & C & C & C & C \\
\hline Emotional instability & Subscale neuroticism of NEO-FF-I [52] (Q) & & C & & & & \\
\hline Caregiver management strategy & Caregiver management strategy [15] (SI) & & C & C & C & C & C \\
\hline \multicolumn{8}{|l|}{ Additional variables } \\
\hline In/exclusion criteria & & C & & & & & \\
\hline Informed consent & & C & & & & & \\
\hline Demographic data & $\begin{array}{l}\text { Age, gender, education level, marital status, } \\
\text { employment }\end{array}$ & & C & & & & \\
\hline
\end{tabular}


Table 1: Flowchart of measures used during the assessments (Continued)

\begin{tabular}{|c|c|c|c|c|c|c|}
\hline Information on informal care & $\begin{array}{l}\text { hours giving care, contact hours, other } \\
\text { informal caregivers }\end{array}$ & C & C & C & C & C \\
\hline Information on employment & Hours working, date stopped working & C & C & C & C & C \\
\hline \multicolumn{7}{|l|}{ Children } \\
\hline Needs and experiences & $(\mathrm{SSI})$ & Ch & & & & \\
\hline Demographic data & $\begin{array}{l}\text { Age, gender, education level, employment, } \\
\text { living situation }\end{array}$ & Ch & & & & \\
\hline Data on informal care & $\begin{array}{l}\text { Hours spent care giving, contact hours with } \\
\text { demented parent }\end{array}$ & Ch & & & & \\
\hline
\end{tabular}

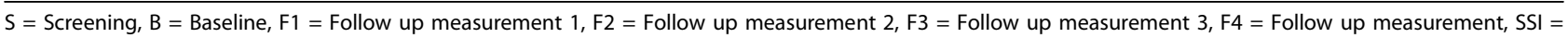
Semi Structured Interview, $\mathrm{SI}=$ Structured Interview, CT = Cognitive Test, $\mathrm{Q}=$ Questionnaire, RS = Rating Scale, C = informant is caregiver, $\mathrm{P}=$ Informant is patient, $\mathrm{N}=$ Informant is health care professional from nursing home, $\mathrm{Ch}=$ informant is child

between groups will be made with independent samples T-tests or $\mathrm{AN}(\mathrm{C}) \mathrm{OVAs}$ for continuous and normally distributed variables and Pearson's Chi square test, Fisher's exact or Mann-Whitney U tests for categorical and non-normally distributed variables. Comparisons between the memory clinic and day care groups, the EOD group and the LOD group and within groups across measurements will be performed using linear mixed models analyses. A survival analysis will be performed to study predictors of institutionalization. If participants withdraw from the study, they will not be excluded. The data collected can still be analyzed, because of the use of linear mixed models. However, the characteristics of the dropouts and losses to follow-up will be described and taken into account.

Qualitative data will be analyzed using the method of constant comparative analysis [51]. These qualitative analyses will be performed in order to obtain a more indepth, complex view and understanding of the experiences of EOD patients and their family members. The interviews that are held with the caregivers will be fully transcribed and first read by one researcher. They will then be read a second time to develop codes that will eventually be grouped into categories. Categories will then be grouped into themes. Another researcher will independently apply the same procedure. The analyses will be performed using Atlas.ti.

\section{Discussion}

The current paper presents the study protocol of a prospective cohort study: the NeedYD-study. This project mainly focuses on the course of EOD, the functional characteristics of EOD patients, the needs of EOD patients and their caregivers, the risk factors for institutionalization and the interaction with the caring environment.

To our knowledge, this is the first study that addresses these issues longitudinally in a large cohort. It will contribute widely to our knowledge about the course of EOD, the caring process and the needs of the patient and caregiver as they develop during the course of the disease. A longitudinal design is necessary to examine the predictive value of study variables in observational data. Despite the many positive aspects of this design, there are some limitations.

Sample bias could be a factor in our study. Although patients are recruited through a large range of different institutions, which is likely to be representative of the Dutch population, the group that gives consent may be different from the group that refuses to participate. Furthermore, selective attrition due to early death is inherently associated with the current study.

In addition, the data from the present study and the historical cohort of the LOD sample (MaasBED study) are different in several ways, as the participants are not matched. The LOD patients were mostly seen right after receiving the diagnosis, whereas in the EOD group patients in different stages are included. The EOD group is, therefore, probably more heterogeneous in terms of disease severity, cognitive functioning and ADL disability. Furthermore, the dementia of the EOD patients is possibly more severe because establishing a diagnosis in EOD often takes longer than in LOD. However, these factors as well as other possible confounders are collected in order to take these into account during the statistical analyses.

Furthermore, one may argue that the proxy ratings we use for several patient characteristics are not as reliable as patient ratings. However, in this patient group such ratings are inevitable since dementia patients gradually become cognitively impaired and may suffer from a lack of awareness. Therefore, proxy ratings are preferred to keep the informant during follow-up reliable and constant.

In conclusion, the strong points of this study outweigh its few limitations as long as they are dealt with properly.

\section{Acknowledgements}

This study is supported by a grant of The Dutch Alzheimer's Foundation, Bunnik, the Netherlands, a grant of the Florence Care Group, The Hague, the Netherlands and a grant of SWBV (Stichting Wetenschapsbevordering Verpleeghuiszorg), Utrecht, the Netherlands. 


\section{Author details}

'School for Mental Health and Neuroscience, Alzheimer Center Limburg, Maastricht University Medical Center, Maastricht, the Netherlands. ${ }^{2}$ Florence, Mariahoeve, Center for Specialized Care in Early Onset Dementia, Den Haag, the Netherlands. ${ }^{3}$ Department of Primary and Community Care: Center for Family Medicine, Geriatric Care and Public Health, Radboud University Nijmegen, Medical Centre, Nijmegen, the Netherlands. ${ }^{4}$ Scientific Institute for Quality of Healthcare/Alzheimer Center Nijmegen, Radboud University Nijmegen, Medical Centre, Nijmegen, The Netherlands. ${ }^{5}$ Kalorama Foundation, Beek-Ubbergen, the Netherlands.

\section{Authors' contributions}

The presented study was designed by FV, RK and MdV. DVV wrote the article and $\mathrm{CB}$ assisted with writing the article. FV, RK, MV and MdV critically reviewed the article. All authors read and approved the final manuscript.

\section{Competing interests}

The authors declare that they have no competing interests.

Received: 9 February 2010 Accepted: 12 March 2010 Published: 12 March 2010

\section{References}

1. Harvey RJ, Rossor MN, Skelton-Robinson M, Garralda E: Young onset dementia: epidemiology, clinical symptoms, family burden, support and outcome. Imperial college of science, technology and medicine Dementia research group 1998.

2. Harvey RJ, Skelton-Robinson M, Rossor MN: The prevalence and causes of dementia in people under the age of 65 years. Journal of Neurology, Neurosurgery \& Psychiatry 2003, 74:1206-1209.

3. Sulkava R: Prevalence of severe dementia in Finland. Neurology 1985, 35:1025-1029.

4. Werner P, Stein-Shvachman I, Korczyn AD: Early onset dementia: clinical and social aspects. Int Psychogeriatr 2009, 1-6.

5. Van Vliet D, De Vugt ME, Bakker C, Koopmans R, Verhey FRJ: Impact of early onset dementia on caregivers: a review. International Journal of Geriatric Psychiatry

6. Sampson EL, Warren JD, Rossor MN: Young onset dementia. Postgrad Med J 2004, 80:125-139.

7. Mendez MF: The accurate diagnosis of early-onset dementia. Int $\mathrm{J}$ Psychiatry Med 2006, 36:401-412.

8. Van Vliet D, Bakker C, De Vugt ME, Koopmans RTCM, Verhey FRJ: How do caregivers of patients with early onset dementia perceive the period prior to diagnosis. Abstract book of the 19th Alzheimer Europe Conference: 28-30 May, 2009, Brussels. Errata Corrige 2009, 2.

9. de Vugt ME, Stevens F, Aalten P, Lousberg R, Jaspers N, Winkens I, Jolles J Verhey FRJ: Behavioural disturbances in dementia patients and quality of the marital relationship. International Journal of Geriatric Psychiatry 2003, 18:149-154.

10. Knopman DS, Kitto J, Deinard S, Heiring J: Longitudinal study of death and institutionalization in patients with primary degenerative dementia. Journal of the American Geriatrics Society 1988, 36:108-112.

11. Steele C, Rovner B, Chase GA, Folstein M: Psychiatric symptoms and nursing home placement of patients with Alzheimer's disease. American Journal of Psychiatry 1990, 147:1049-1051.

12. Gaugler JE, Yu F, Krichbaum K, Wyman JF: Predictors of nursing home admission for persons with dementia. Medical Care 2009, 47:191-198.

13. de Vugt ME, Stevens F, Aalten P, Lousberg R, Jaspers N, Verhey FRJ: A prospective study of the effects of behavioral symptoms on the institutionalization of patients with dementia. International Psychogeriatrics 2005, 17:577-589.

14. Aalten P, van Valen E, de Vugt ME, Lousberg R, Jolles J, Verhey FRJ: Awareness and behavioral problems in dementia patients: A prospective study. International Psychogeriatrics 2006, 18:3-17.

15. de Vugt ME, Stevens F, Aalten P, Lousberg R, Jaspers N, Winkens I, Jolles J, Verhey FRJ: Do caregiver management strategies influence patient behaviour in dementia? International Journal of Geriatric Psychiatry 2004, 19:85-92.

16. Zuidema SU, de Jonghe JFM, Verhey FRJ, Koopmans RTCM: Neuropsychiatric symptoms in nursing home patients: Factor structure invariance of the Dutch nursing home version of the Neuropsychiatric
Inventory in different stages of dementia. Dementia and Geriatric Cognitive Disorders 2007, 24:169-176.

17. Zuidema SU, Derksen E, Verhey FRJ, Koopmans RTCM: Prevalence of neuropsychiatric symptoms in a large sample of Dutch nursing home patients with dementia. International Journal of Geriatric Psychiatry 2007, 22:632-638.

18. Aalten P, de Vugt ME, Jaspers N, Jolles J, Verhey FRJ: The course of neuropsychiatric symptoms in dementia. Part I: Findings from the twoyear longitudinal Maasbed study. International Journal of Geriatric Psychiatry 2005, 20:523-530.

19. de Vugt ME, Riedijk SR, Aalten P, Tibben A, van Swieten JC, Verhey FR: Impact of behavioural problems on spousal caregivers: a comparison between Alzheimer's disease and frontotemporal dementia. Dement Geriatr Cogn Disord 2006, 22:35-41.

20. American Psychiatric Association (2000) Diagnostic and Statistical manual of mental Disorders-Text revision: DSM-IV-TR. American Psychiatric Association.

21. McKhann G, Drachman D, Folstein M, Katzman R, Price D, Stadlan EM: Clinical diagnosis of Alzheimer's disease: report of the NINCDS-ADRDA Work Group under the auspices of Department of Health and Human Services Task Force on Alzheimer's Disease. Neurology 1984, 34:939-944.

22. McKeith IG: Consensus guidelines for the clinical and pathologic diagnosis of dementia with Lewy bodies (DLB): report of the Consortium on DLB International Workshop. J Alzheimers Dis 2006, 9:417-423.

23. Neary D, Snowden JS, Gustafson L, Passant U, Stuss D, Black S, Freedman M, Kertesz A, Robert PH, Albert M, et al: Frontotemporal lobar degeneration: a consensus on clinical diagnostic criteria. Neurology 1998, 51:1546-1554.

24. Mesulam MM, Grossman M, Hillis A, Kertesz A, Weintraub S: The core and halo of primary progressive aphasia and semantic dementia. Ann Neurol 2003, 54(Suppl 5):S11-14.

25. Erkinjuntti T: Clinical criteria for vascular dementia: The NINDS-AIREN criteria. Dementia 1994, 5:189-192.

26. Reynolds T, Thronicroft G, Abas M, Woods B, Hoe J, Leese M, Orrell M: Camberwell Assessment of Need for the Elderly (CANE): Development, validity and reliability. British Journal of Psychiatry 2000, 176:444-452.

27. Cummings JL, Mega M, Gray K, Rosenberg-Thompson S: The Neuropsychiatric Inventory: Comprehensive assessment of psychopathology in dementia. Neurology 1994, 44:2308-2314.

28. Wood S, Cummings JL, Hsu M-A, Barclay T, Wheatley MV, Yarema KT, Schnelle JF: The use of the Neuropsychiatric Inventory in nursing home residents: Characterization and measurement. American Journal of Geriatric Psychiatry 2000, 8:75-83.

29. Kat MG, de Jonghe JFM, Aalten P, Kalisvaart CJ, Dröes RM, Verhey FRJ Neuropsychiatrische symptomen bij dementie: Psychometrische aspecten van de Nerlandse Neuropsychiatric Inventory (NPI). Tijdschrift voor Gerontologie en Geriatrie 2002, 33:150-155.

30. Kaufer DI, Cummings IL, Christine D, Bray T, Castellon S, Masterman D, MacMillan A, Ketchel P, DeKosky ST: Assessing the impact of neuropsychiatric symptoms in Alzheimer's disease: The Neuropsychiatric Inventory Caregiver Distress Scale. Journal of the American Geriatrics Society 1998, 46:210-215.

31. Reisberg B, Ferris SH, de Leon MJ, Crook T: The Global Deterioration Scale for assessment of primary degenerative dementia. American Journal of Psychiatry 1982, 139:1136-1139.

32. Teunisse S, Derix MM: Meten van het dagelijks functioneren van thuiswonende dementiepatiënten: ontwikkeling van een vragenlijst. Tijdschrift voor Gerontologie en Geriatrie 1991, 22:53-59.

33. Folstein MF, Folstein SE, McHugh PR: Mini-mental state: A practical method for grading the cognitive state of patients for the clinician. Journal of Psychiatric Research 1975, 12:189-198.

34. Saxton J, Kastango KB, Hugonot-Diener L, Boller F, Verny M, Sarles CE, Girgis RR, Devouche E, Mecocci P, Pollock BG, DeKosky ST: Development of a Short Form of the Severe Impairment Battery. American Journal of Geriatric Psychiatry 2005, 13:999-1005.

35. de Jonghe JF, Wetzels RB, Mulders A, Zuidema SU, Koopmans RT: Validity of the Severe Impairment Battery Short Version. I Neurol Neurosurg Psychiatry 2009, 80:954-959.

36. Dubois B, Slachevsky A, Litvan I, Pillon B: The FAB: A frontal assessment battery at bedside. Neurology 2000, 55:1621-1626.

37. Verhey FR, Rozendaal N, Ponds RW, Jolles J: Dementia, awareness and depression. International Journal of Geriatric Psychiatry 1993, 8:851-856. 
38. Zanetti O, Vallotti B, Frisoni GB, Geroldi C, Bianchetti A, Pasqualetti P, Trabucchi M: Insight in dementia: When does it occur? Evidence for a nonlinear relationship between insight and cognitive status. Journals of Gerontology: Series B: Psychological Sciences and Social Sciences 1999, P100-p106.

39. Verhey FRJ, Ponds RWHM, Rozendaal N, Jolles J: Depression, insight, and personality changes in Alzheimer's disease and vascular dementia. Journal of Geriatric Psychiatry and Neurology 1995, 8:23-27.

40. Thorgrimsen L, Selwood A, Spector A, Royan L, de Madariaga Lopez M, Woods RT, Orrell M: Whose Quality of Life Is It Anyway? The Validity and Reliability of the Quality of Life-Alzheimer's Disease (QoL-AD) Scale. Alzheimer Disease \& Associated Disorders 2003, 17:201-208.

41. Alexopoulos GS, Abrams RC, Young RC, Shamoian CA: Cornell Scale for Depression in Dementia. Biological Psychiatry 1988, 23:271-284.

42. Wimo A, Winblad B: Resource Utilization in Dementia: "RUD Lite". Brain Aging 2003, 3:48-59.

43. Vernooij-Dassen MJFJ, Felling AJA, Brummelkamp E, Dauzenberg MGH, van den Bos GAM, Grol R: Assessment of caregiver's competence in dealing with the burden of caregiving for a dementia patient: A Short Sense of Competence Questionnaire (SSCQ) suitable for clinical practice. Journal of the American Geriatrics Society 1999, 47:256-257.

44. Davidson J, Turnbull CD, Strickland R, Miller R: The Montgomery-Asberg Depression Scale: Reliability and validity. Acta Psychiatrica Scandinavica 1986, 73:544-548.

45. Arindell WA, Ettema JHM: SCL-90 Herziene handleiding bij een multidimensionele psychopathologie indicator Lisse: Swets Publishers 2003.

46. Costa PTJ, McCrae RR: Revised NEO Personality Inventory (NEO-PI-R) and NEO Five-Factor Inventory (NEO-FFl) Professional Manual Odessa FL: Psychological Assessment Resources 1992.

47. Schreurs PJG, Willige G, Brosschot JF, Telegen B, Graus GMH: Handleiding Utrechtse Coping Lijst UCL (herziene versie) Lisse: Swets \& Zeitlinger 1993.

48. Hays RD, Morales LS: The RAND-36 measure of health-related quality of life. Annals of Medicine 2001, 33:350-357.

49. Zee Van der Kl, Sandemann R: Het meten van de algemene gezondheidstoestand met de RAND-36: een handleiding (Measurement of general health with the RAND-36: a manual). Noordelijk Centrum voor Gezondheidsvraagstukken Rijksuniversiteit Groningen 1993.

50. Lawrence RH, Tennstedt SL, Assmann SF: Quality of the caregiver-care recipient relationship: Does it offset negative consequences of caregiving for family caregivers? Psychology and Aging 1998, 13:150-158.

51. Corbin J, Strauss A: Grounded Theory Research: Procedures, Canons, and Evaluative Criteria. Qualitative Sociology Springer Science \& Business Media B.V. 1990, 13:3.

52. Costa PT, McCrae RR: Normal personality assessment in clinical practice: The NEO Personality Inventory. Psychological Assessment 1992, 4:5-13.

\section{Pre-publication history}

The pre-publication history for this paper can be accessed here:http://www. biomedcentral.com/1471-2318/10/13/prepub

doi:10.1186/1471-2318-10-13

Cite this article as: van Vliet et al: Research protocol of the NeedYDstudy (Needs in Young onset Dementia): a prospective cohort study on the needs and course of early onset dementia. BMC Geriatrics 2010 10:13.

\section{Submit your next manuscript to BioMed Central and take full advantage of:}

- Convenient online submission

- Thorough peer review

- No space constraints or color figure charges

- Immediate publication on acceptance

- Inclusion in PubMed, CAS, Scopus and Google Scholar

- Research which is freely available for redistribution

Submit your manuscript at www.biomedcentral.com/submit
Biomed Central 